\title{
Silk Amino Acids Improve Physical Stamina and Male Reproductive Function of Mice
}

\author{
Sunhee Shin, ${ }^{a, \#}$ Seongho Yeon,,${ }^{b, \#}$ Dongsun PARK, ${ }^{a}$ Jiyoung OH, ${ }^{a}$ Hyomin Kang, ${ }^{a}$ Sunghyun Kim,${ }^{a}$ \\ Seong Soo Joo, ${ }^{a}$ Woo-Taek Lim, ${ }^{b}$ Jeong-Yong LeE, ${ }^{b}$ Kyung-Chul CHOI, ${ }^{a}$ Ki Yon Kim, ${ }^{c}$ \\ Seung Up KIM, ${ }^{c}$ Jong-Choon $\mathrm{KIM}^{d}{ }^{d}$ and Yun-Bae KIM${ }^{*, a, c}$ \\ ${ }^{a}$ College of Veterinary Medicine and Research Institute of Veterinary Medicine, Chungbuk National University; 410 \\ Seongbongro (Gaeshin-dong), Cheongju, Chungbuk 361-763, Republic of Korea: ${ }^{b}$ Worldway Co., Ltd.; 618 Shinjeong-ri, \\ Jeoneui-myeon, Yeongi-gun, Chungnam 339-853, Republic of Korea: ${ }^{c}$ Department of Medicine, University of British \\ Columbia Hospital; 2211 Wesbrook Mall, Vancouver, BC V6T 2B5, Canada: and d College of Veterinary Medicine, \\ Chonnam National University; 333 Yongbongro, Buk-gu, Gwangju 500-757, Republic of Korea.
}

Received August 18, 2009; accepted November 11, 2009

The effects of a silk amino acid (SAA) preparation on the physical stamina and male reproductive function of mice were investigated. Eight-week-old male ICR mice (29-31 g) were orally administered SAA (50, 160 or $500 \mathrm{mg} / \mathrm{kg}$ ) for $44 \mathrm{~d}$ during 30 -min daily swimming exercise. The mice were subjected to a weight-loaded (5\% of body weight) forced swimming on the 14th, 28 th and 42 nd day to determine maximum swimming time, and after a 2-d recovery period (treated with SAA without swimming exercise), parameters related to fatigue and reproductive function were analyzed from blood, muscles and reproductive organs. Repeated swimming exercise increased the maximum swimming time to some extent, in spite of a marked reduction in body weight gain, and SAA further enhanced the stamina in a dose-dependent manner. Forced swimming exercises increased blood parameters of tissue injury, but depleted blood glucose and tissue glycogen, which were substantially prevented by SAA treatment. In addition, SAA significantly reduced the muscular thiobarbituric acid-reactive substances and blood corticosterone content increased by forced swimming. Swimming exercise decreased the blood testosterone level, which was recovered by SAA, leading to enhanced sperm counts. These combined results indicate that SAA not only enhances physical stamina by minimizing damage to tissues, including muscles, as well as preventing energy depletion caused by swimming stress, but also improves male reproductive function by increasing testosterone and sperm counts.

Key words silk amino acid preparation; stamina; swimming time; male reproductive function; sperm count

Silks are protein polymers that differ in their components and structures according to the insects producing the silk. ${ }^{1)}$ Silks from silkworm (Bombyx mori) and spiders (Nephila clavipes and Araneus diadematus) are composed of 2 major peptides, sericin and fibroin, ${ }^{2)}$ which are well known to have pharmacological activities including anti-diabetic effect. ${ }^{3-9)}$

Hydrolysis of silk proteins from silkworms leads to different peptide sizes, which eventually creates peptides that are 18-19 amino acids in length, while enzymatic degradation results in specific sizes or compositions of peptides ${ }^{10,11)}$ exerting diverse bioactivities ${ }^{4,12,13)}$ such as anti-diabetic, ${ }^{5-9)}$ hypocholesterolemic, ${ }^{10,14,15)}$ anti-oxidant, ${ }^{16,17)}$ immunoregulatory, ${ }^{18)}$ anti-tumor, ${ }^{17,19)}$ anti-viral, ${ }^{20)}$ anti-bacterial ${ }^{21)}$ effects.

Silk amino acids (SAA) were also shown to decrease blood triglycerides and to preserve hepatic function. ${ }^{10,14)}$ In our previous studies, we found that repeatedly treating resting rats with a SAA preparation lowered blood levels of tissue injury parameters from the muscles and the liver. ${ }^{22)}$ Also, it increased glucose and albumin levels, and potentiated hematopioesis including lymphocyte counts. Furthermore, a high dose $(800 \mathrm{mg} / \mathrm{kg})$ of SAA exerted stamina-enhancing activity in forced swimming mice by preventing tissue injuries and increasing anti-fatigue parameters. ${ }^{23)}$ Such effects led us to investigate the effects of a SAA preparation on the physical stamina (energy-boosting) and male reproductive function in a forced swimming model.

Forced swimming tests have been used to evaluate the behavioral performances of rodents to predict the efficacy of anti-depressant treatments, ${ }^{24-26)}$ since the animals exhibit immobility behavior considered a depression-like response, as a reflection of helplessness when subjected to an incapable situation. ${ }^{27)}$ Similarly, weight-loaded swimming tests have also been used as a reference for measuring the fatigue level objectively and quantitatively. ${ }^{28-30)}$ Recently, forced swimming tests were adopted not only to assess adjustment of rodents, but also to evaluate male reproductive function under repeated stress situations. ${ }^{30-33)}$

The aim of the present study was to determine the effects of SAA, an amino acid preparation from silk (cocoon), on physical stamina and male reproductive function. Especially, we analyzed not only the maximum swimming time and blood and tissue parameters of muscular and hepatic injuries, but also hormone concentration and sperm counts following weight-loaded forced swimming.

\section{MATERIALS AND METHODS}

Materials A preparation of SAA from acid $(\mathrm{HCl})$ hydrolysate of silk proteins was obtained from Worldway Co., Ltd. (Jeoneui, Korea). The SAA preparation was mainly composed of Ala $(34.36 \%)>$ Gly $(27.23 \%)>\operatorname{Ser}(9.58 \%)>$ Val $(3.49 \%)>\operatorname{Thr}(2.00 \%)$, and minor amino acids. ${ }^{23)}$

Animals Eight-week-old male ICR mice (29-31 g, $n=10$ per group) were procured from the Daehan Laboratory Animal Center (Eumseong, Korea). The animals were maintained at a constant temperature $\left(23 \pm 2{ }^{\circ} \mathrm{C}\right)$, relative humidity

\# These authors contributed equally to this work. 
of $55 \pm 10 \%$ and 12-h light/dark cycle. The animals were fed with standard rodent chow and purified water ad libitum. All experimental procedures were approved and carried out in accordance with the Institutional Animal Care and Use Committee of Laboratory Animal Research Center at Chungbuk National University, Korea.

Treatment and Forced Swimming To allow the mice to adapt to a swimming pool with a constant water temperature of $25 \pm 0.5^{\circ} \mathrm{C}$, all mice swam for $30 \mathrm{~min} 4 \mathrm{~d}$ before the experiment. The mice were divided into two main groups: resting and swimming exercise groups. The animals in the exercise groups were administered freeze-dried SAA (50, 160 or $500 \mathrm{mg} / \mathrm{kg}$ ) or its vehicle (water, $5 \mathrm{ml} / \mathrm{kg}$ ) by gavage for $44 \mathrm{~d}$, and swam for $30 \mathrm{~min}$ daily $30 \mathrm{~min}$ after the treatment during the experimental period except the days of the forced swimming test.

All mice were subjected to a weight-loaded forced swimming exercise on the 14th, 28th and 42nd day $30 \mathrm{~min}$ after treatment. The mice were loaded with a lead ring weighing $5 \%$ of their body weight to the tail, and were then placed in the swimming pool. ${ }^{27,30)}$ The test was induced by forcing animals to swim until exhaustion, which was determined by observing loss of coordinated movements and failure to return to the water surface within $7 \mathrm{~s}$. This 7 -s cut-off time was used as a criterion of the maximum swimming capacity of the animal.

Necropsy and Biochemistry After $44 \mathrm{~d}$ of treatment with the SAA preparation and a 2 -d recovery period following the maximum swimming test on day 42 , the mice were fasted for $4 \mathrm{~h}$, and sacrificed under ether anesthesia. Blood was collected and serum concentrations of tissue-injury parameters such as creatine phosphokinase (CPK), aspartate transaminase (AST), lactate dehydrogenase (LDH), alanine transaminase (ALT), blood urea nitrogen (BUN), creatinine and lactate as well as anti-fatigue parameters including glucose and total proteins (TP) were determined using an autoanalyzer. $^{23,27,30,34)}$ The gastrocnemius muscles, liver, spleen, thymus, adrenal glands, testes and epididymides, the organs susceptible or related to exhaustion and reproduction, were removed and weighed.

Measurement of Hepatic and Muscular Glycogen Samples of frozen tissues $(30 \mathrm{mg})$ were hydrolyzed in $0.3 \mathrm{ml}$ of $30 \%$ potassium hydroxide $(\mathrm{KOH})$ solution in a boiling water bath for 30 min under intermittent shaking. After cooling to room temperature, $0.1 \mathrm{ml}$ of $1 \mathrm{~m}$ sodium sulfate and $0.8 \mathrm{ml}$ of ethanol were added. The samples were boiled again for $5 \mathrm{~min}$ to facilitate precipitation of glycogen, and then centrifuged at $10000 \mathrm{~g}$ for $5 \mathrm{~min}$. The glycogen pellet was dissolved in $0.2 \mathrm{ml}$ of water, and two additional ethanol precipitations were performed. The final pellet was dried and dissolved in $0.2 \mathrm{ml}$ amyloglucosidase $(0.3 \mathrm{mg} / \mathrm{ml})$ in $0.2 \mathrm{M}$ sodium acetate buffer $(\mathrm{pH} 4.8)$ and incubated for $3 \mathrm{~h}$ at $40{ }^{\circ} \mathrm{C}$. The reaction mixture was then diluted two-fold with water. To determine the glucose concentration, the diluted sample was added to the glucose assay solution which contains triethanolamine- $\mathrm{KOH}(\mathrm{pH} 7.5)$, adenosine $5^{\prime}$ triphosphate, $\beta$-nicotinamide adenine dinucleotide phosphate, and glucose-6-phosphate dehydrogenase as previously described. ${ }^{35)}$ The absorbance at $340 \mathrm{~nm}$ was determined before and after addition of hexokinase.

Measurement of Muscular Thiobarbituric Acid-Reac- tive Substances (TBARS) The gastrocnemius muscles were minced and homogenized in 9 volumes of cold phosphate-buffered saline (PBS, $\mathrm{pH} 7.4$ ) for $2 \mathrm{~min}$ at $4{ }^{\circ} \mathrm{C}$ using a tissue homogenizer. $0.5 \mathrm{ml}$ sodium dodecyl sulfate $(8.1 \%)$ and acetic acid $(1 \mathrm{ml})$ solutions were added to the homogenate $(0.5 \mathrm{ml})$ and vortex-mixed. After adding $0.5 \mathrm{ml}$ TBA solution $(0.75 \%)$, the mixture was boiled for $60 \mathrm{~min}$ at $95^{\circ} \mathrm{C}$. After rapid cooling to room temperature and centrifuge, the absorbance of the supernatant was read at $532 \mathrm{~nm}$, and quantified from a standard calibration curve using 1,1,3,3-tetraethoxypropane. ${ }^{36}$

Hormone Analysis Serum concentrations of corticosterone and testosterone were analyzed by solid phase radioimmunoassay with ${ }^{125} \mathrm{I}$ (sensitivity $=0.04 \mathrm{ng} / \mathrm{ml}$ : intra- and inter-assay coefficients of variations were 8.4 and 15.2, respectively) (Molecular Device, Emax, U.S.A.).

Sperm Counts and Motility The testes of each animal were homogenized in 9 volumes of PBS for $2 \mathrm{~min}$, and sonicated at $4^{\circ} \mathrm{C}$ for $3 \mathrm{~min}$ to obtain homogenization-resistant sperm heads. The number of sperm heads was counted using a hemacytometer. ${ }^{37,38)}$ Epididymal sperms were flushed out into Hank's balanced salt solution ( $\mathrm{pH} 7.2)$ containing bovine serum albumin $(5 \mathrm{mg} / \mathrm{ml})$. After 10 -min incubation at $37^{\circ} \mathrm{C}$, an aliquot $(5 \mu \mathrm{l})$ of the culture medium was placed into a microwarm plate $\left(37^{\circ} \mathrm{C}\right)$ with cover glass, and the rate $(\%)$ of motile sperms was counted under a light microscope $(\times 400)^{37)}$

Statistical Analysis The results are presented as means \pm S.D. The significance of differences of all results were analyzed by one-way analysis of variance (ANOVA) followed by the Tukey's test correction.

\section{RESULTS}

Daily swimming exercise for $30 \mathrm{~min}$ remarkably lowered the body weight gain by $10-20 \%$ compared to that of resting animals (Fig. 1). In addition, weight-loaded forced swimming, which was conducted to determine maximum swimming time on days 14, 28 and 42, caused marked, but transient, body weight loss. This exercise-induced reduction of body weight gain was somewhat facilitated by SAA treatment.

Repeated swimming performance increased the maximum swimming time to some extent $(30-50 \%)$, in spite of a reduced body weight gain (Fig. 2). Fourteen-, 28- and 42-d administration of the SAA preparation further enhanced the maximum swimming time in a dose-dependent manner. Although only a high dose $(500 \mathrm{mg} / \mathrm{kg})$ of SAA significantly increased $(35.9 \%)$ the maximum swimming time on day 14 , long-term administration ( $\geqq 28 \mathrm{~d}$ ) of medium $(160 \mathrm{mg} / \mathrm{kg}$ ) and high $(500 \mathrm{mg} / \mathrm{kg})$ doses markedly improved the physical stamina, resulting in a $58.8 \%$ and $121.4 \%$ increases on day 42.

Daily swimming exercise and forced swimming tests on days 14, 28 and 42 tended to decrease the weights of the liver and thymus, but slightly increased those of the adrenal glands, epididymides and muscles (Table 1). The changes in the weight of the liver, thymus and adrenal glands were recovered by supplementing the SAA preparation. Especially, SAA further increased the mass of gastrocnemius muscles directly related to exercise, in addition to slightly increasing 
the weight of the testes and epididymides.

Forced swimming exercises increased blood damage markers of the muscles (increases in CPK, AST and LDH) and liver (increases in AST, ALT and LDH), induced accumulations of nitrogen (BUN), creatinine and lactic acid (Table 2), and depleted energy sources (decreases in blood glucose and TP as well as hepatic and muscular glycogen) (Table 3). In-

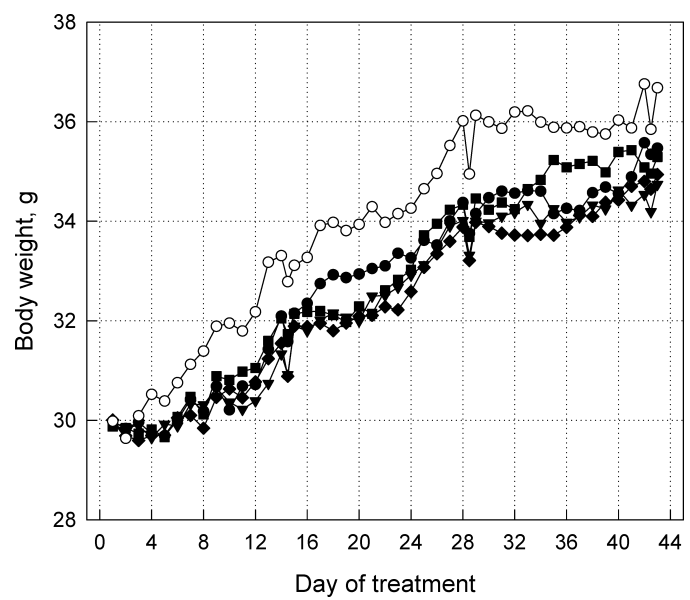

Fig. 1. Change in Body Weight of Mice Treated with a Silk Amino Acid (SAA) Preparation during 30-min Daily Swimming Exercises

The mice were subjected to forced swimming on days 14,28 and $42 . \bigcirc$, resting control; $\bullet$, swimming exercise; $\boldsymbol{\nabla}$, swimming $+50 \mathrm{mg} / \mathrm{kg}$ SAA; $\mathbf{\square}$, swimming $+160 \mathrm{mg} / \mathrm{kg} \mathrm{SAA} ;$, swimming $500 \mathrm{mg} / \mathrm{kg} \mathrm{SAA}$. Error bars and significance marks were omitted to show the symbols more clearly. terestingly, exercise-induced increase or depletion in the blood and tissue parameters were substantially attenuated or supplemented by treatment with the SAA preparation.

The TBARS content in the gastrocnemius muscles was remarkably increased after daily swimming exercise and exhaustive forced swimming (about 20\%) (Fig. 3). Such an increase in lipid peroxidation was suppressed by the SAA preparation in a dose-dependent manner, to a normal level even at a low dose $(50 \mathrm{mg} / \mathrm{kg})$, and further at doses $\geqq 160$ $\mathrm{mg} / \mathrm{kg}$.

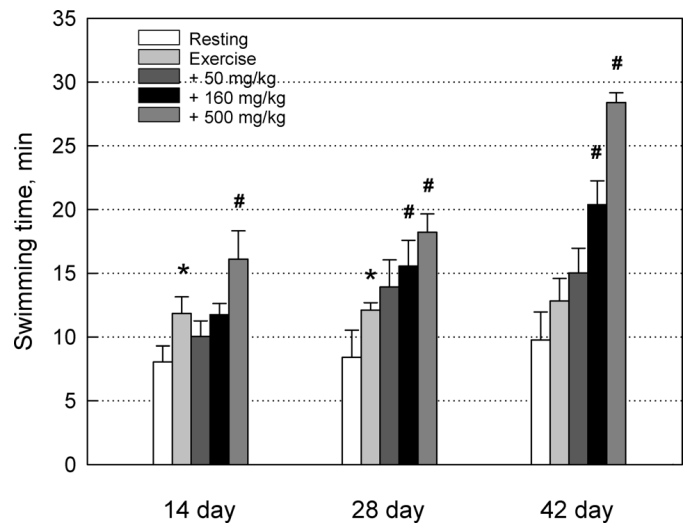

Fig. 2. The Maximum Swimming Time of Mice Treated with a Silk Amino Acid (SAA) Preparation for 14, 28 or $42 \mathrm{~d}$ during 30-min Daily Swimming Exercises

* Significantly different from resting control $(p<0.05)$. \# Significantly different from exercise (swimming) alone $(p<0.05)$.

Table 1. Absolute (g) and Relative (\%) Organ Weights of Mice Treated with a Silk Amino Acid (SAA) Preparation for 44 d during 30-min Daily Swimming Exercise

\begin{tabular}{|c|c|c|c|c|c|c|c|c|}
\hline Treatn & ent (mg/kg) & Liver & Spleen & Thymus & Adrenals & Testes & Epididymides & Muscles \\
\hline \multirow{5}{*}{$\begin{array}{l}\text { Absolute } \\
\text { (g) }\end{array}$} & Resting & $1.90 \pm 0.26$ & $0.1090 \pm 0.0094$ & $0.0468 \pm 0.0211$ & $0.0067 \pm 0.0018$ & $0.220 \pm 0.034$ & $0.0451 \pm 0.0090$ & $0.333 \pm 0.042$ \\
\hline & Exercise & $1.75 \pm 0.14$ & $0.1069 \pm 0.0137$ & $0.0420 \pm 0.0135$ & $0.0078 \pm 0.0019$ & $0.223 \pm 0.019$ & $0.0477 \pm 0.0083$ & $0.347 \pm 0.055$ \\
\hline & $+\operatorname{SAA}(50)$ & $1.89 \pm 0.11$ & $0.1125 \pm 0.0120$ & $0.0502 \pm 0.0151$ & $0.0078 \pm 0.0013$ & $0.233 \pm 0.023$ & $0.0477 \pm 0.0093$ & $0.389 \pm 0.038^{\#}$ \\
\hline & + SAA $(160)$ & $1.85 \pm 0.16$ & $0.0956 \pm 0.0122$ & $0.0544 \pm 0.0174$ & $0.0080 \pm 0.0016$ & $0.240 \pm 0.022$ & $0.0464 \pm 0.0077$ & $0.385 \pm 0.057$ \\
\hline & + SAA $(500)$ & $1.84 \pm 0.14$ & $0.1093 \pm 0.0121$ & $0.0608 \pm 0.0113^{\#}$ & $0.0062 \pm 0.0020^{\#}$ & $0.245 \pm 0.006$ & $0.0493 \pm 0.0114$ & $0.397 \pm 0.033^{\#}$ \\
\hline \multirow{5}{*}{$\begin{array}{c}\text { Relative } \\
(\%)\end{array}$} & Resting & $5.36 \pm 0.61$ & $0.3084 \pm 0.0285$ & $0.1320 \pm 0.0572$ & $0.0205 \pm 0.0052$ & $0.624 \pm 0.109$ & $0.1283 \pm 0.0291$ & $0.943 \pm 0.135$ \\
\hline & Exercise & $5.12 \pm 0.23$ & $0.3144 \pm 0.0487$ & $0.1243 \pm 0.0436$ & $0.0211 \pm 0.0052$ & $0.654 \pm 0.069$ & $0.1402 \pm 0.0291$ & $0.992 \pm 0.214$ \\
\hline & + SAA $(50)$ & $5.42 \pm 0.37$ & $0.3220 \pm 0.0344$ & $0.1429 \pm 0.0407$ & $0.0224 \pm 0.0043$ & $0.666 \pm 0.069$ & $0.1364 \pm 0.0250$ & $1.112 \pm 0.153$ \\
\hline & + SAA $(160)$ & $5.26 \pm 0.33$ & $0.3064 \pm 0.0346$ & $0.1351 \pm 0.0542$ & $0.0231 \pm 0.0057$ & $0.690 \pm 0.075$ & $0.1393 \pm 0.0242$ & $1.113 \pm 0.170$ \\
\hline & + SAA $(500)$ & $5.34 \pm 0.33$ & $0.3181 \pm 0.0381$ & $0.1766 \pm 0.0316^{\#}$ & $0.0179 \pm 0.0046^{\#}$ & $0.676 \pm 0.052$ & $0.1482 \pm 0.0316$ & $1.155 \pm 0.369^{\#}$ \\
\hline
\end{tabular}

\# Significantly different from exercise (swimming) alone $(p<0.05)$.

Table 2. Blood Parameters of Tissue Damage in Mice Treated with a Silk Amino Acid (SAA) Preparation for 44 d during 30-min Daily Swimming Exercise

\begin{tabular}{|c|c|c|c|c|c|c|c|}
\hline Treatment (mg/kg) & CPK (IU/1) & AST (IU/1) & ALT (IU/1) & LDH (IU/1) & $\begin{array}{c}\text { BUN } \\
(\mathrm{mg} / \mathrm{dl})\end{array}$ & $\begin{array}{c}\text { Creatinine } \\
(\mathrm{mg} / \mathrm{dl})\end{array}$ & $\begin{array}{l}\text { Lactate } \\
(\mathrm{mg} / \mathrm{dl})\end{array}$ \\
\hline Resting & $48.4 \pm 12.7$ & $52.2 \pm 10.9$ & $23.0 \pm 10.2$ & $377.9 \pm 191.2$ & $28.8 \pm 5.6$ & $0.481 \pm 0.15$ & $112.6 \pm 25.4$ \\
\hline Exercise & $108.3 \pm 20.2 *$ & $80.1 \pm 10.3^{*}$ & $32.9 \pm 4.6$ & $438.1 \pm 114.2$ & $41.6 \pm 4.6^{*}$ & $0.583 \pm 0.17 *$ & $145.9 \pm 31.9 *$ \\
\hline + SAA (50) & $88.4 \pm 30.7$ & $56.8 \pm 10.3^{\#}$ & $27.3 \pm 4.6$ & $350.6 \pm 104.2$ & $34.6 \pm 4.6^{\#}$ & $0.503 \pm 0.17$ & $119.5 \pm 23.7$ \\
\hline + SAA (160) & $78.2 \pm 21.5$ & $61.3 \pm 19.5$ & $30.2 \pm 64.9$ & $426.2 \pm 132.2$ & $36.2 \pm 3.3$ & $0.542 \pm 0.13$ & $128.7 \pm 25.4$ \\
\hline+ SAA $(500)$ & $56.2 \pm 25.4^{\#}$ & $57.1 \pm 16.7^{\#}$ & $27.7 \pm 6.7$ & $395.1 \pm 89.4$ & $34.1 \pm 4.2^{\#}$ & $0.484 \pm 0.17$ & $118.4 \pm 18.7^{\#}$ \\
\hline
\end{tabular}

CPK, creatine phosphokinase; AST, asparatate transaminase; ALT, alanine trasaminase; LDH, lactate dehydrogenase; BUN, blood urea nitrogen. * Significantly different from resting control $(p<0.05)$. \# Significantly different from exercise (swimming) alone $(p<0.05)$. 
Table 3. Blood and Tissue Parameters of Anti-fatigue Energy Source in Mice Treated with a Silk Amino Acid (SAA) Preparation for 44 d during 30-min Daily Swimming Exercise

\begin{tabular}{lccc}
\hline \hline Treatment $(\mathrm{mg} / \mathrm{kg})$ & Blood glucose $(\mathrm{mg} / \mathrm{dl})$ & Blood TP $(\mathrm{mg} / \mathrm{dl})$ & Liver glycogen (mg/g tissue) \\
\hline Resting & $245.8 \pm 31.6$ & $7.31 \pm 2.38$ & $1.88 \pm 1.02$ \\
Exercise & $202.6 \pm 10.6^{*}$ & $7.14 \pm 2.07$ & $0.91 \pm 0.38^{*}$ \\
+SAA (50) & $216.8 \pm 30.6$ & $8.30 \pm 1.07^{\#}$ & $1.35 \pm 1.24$ \\
+ SAA (160) & $208.6 \pm 22.3$ & $7.97 \pm 2.93$ & $0.26 \pm 0.13^{*}$ \\
+SAA (500) & $220.1 \pm 16.3$ & $7.99 \pm 2.22$ & $0.61 \pm 0.21^{\#}$ \\
& & $0.78 \pm 0.21^{\#}$ & $1.62 \pm 0.67^{\#}$ \\
\hline
\end{tabular}

TP, total proteins. * Significantly different from resting control $(p<0.05)$. \# Significantly different from exercise $($ swimming $)$ alone $(p<0.05)$.

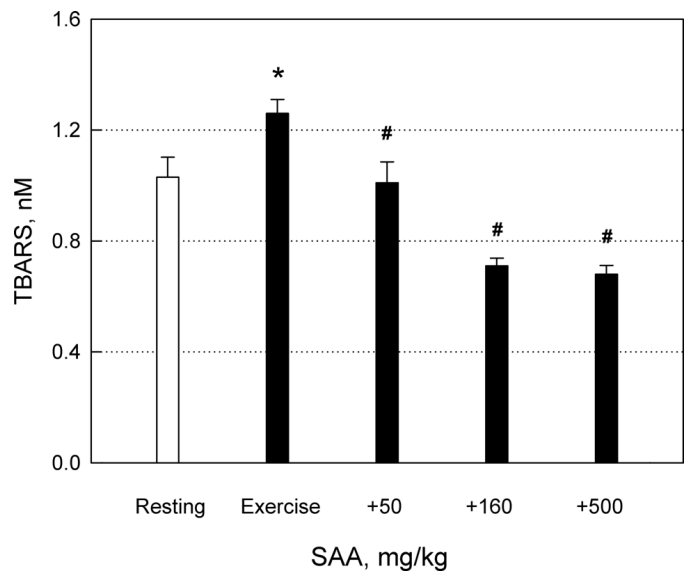

Fig. 3. Muscular Thiobarbituric Acid-Reactive Substances (TBARS) of Mice Treated with a Silk Amino Acid (SAA) Preparation for 44 d during 30min Daily Swimming Exercises

The mice were subjected to forced swimming on days 14,28 and 42 . $*$ Significantly different from resting control $(p<0.05)$. \# Significantly different from exercise (swimming) alone $(p<0.05)$

Table 4. Blood Corticosterone and Testosterone Concentrations of Mice Treated with a Silk Amino Acid (SAA) Preparation for 44 d during 30-min Daily Swimming Exercise

\begin{tabular}{ccc}
\hline \hline Treatment $(\mathrm{mg} / \mathrm{kg})$ & $\begin{array}{c}\text { Corticosterone } \\
(\mathrm{ng} / \mathrm{ml})\end{array}$ & $\begin{array}{c}\text { Testosterone } \\
(\mathrm{pg} / \mathrm{ml})\end{array}$ \\
\hline Resting & $43.5 \pm 24.3$ & $2,828.4 \pm 466.7$ \\
Exercise & $104.3 \pm 21.9^{*}$ & $1,804.0 \pm 577.1^{*}$ \\
+ SAA (50) & $65.9 \pm 19.1^{\#}$ & $4,725.0 \pm 719.5^{\#}$ \\
+ SAA (160) & $50.0 \pm 22.3^{\#}$ & $3,941.0 \pm 134.3^{\#}$ \\
+SAA (500) & $54.2 \pm 15.4^{\#}$ & $2,865.0 \pm 505.5^{\#}$ \\
\hline
\end{tabular}

* Significantly different from resting control $(p<0.05)$. \# Significantly different from exercise (swimming) alone $(p<0.05)$.

Swimming exercises significantly increased the blood corticosterone level to 2.4 folds relative to the control, which was near-fully attenuated by SAA treatment (Table 4). Interestingly, continuing exercise remarkably lowered the blood concentration of testosterone to $64 \%$ of the control value. However, it recovered to a level higher than that of the normal control by SAA treatment, although a dose-dependent effect was not achieved.

Repeated exercise induced negligible effects on the testicular sperm counts and epididymal sperm motility, although sperm counts were slightly lowered (Fig. 4). Daily treatment with SAA $(50-500 \mathrm{mg} / \mathrm{kg})$ during exercise increased testicular sperm counts by $37.7-55.2 \%$, without influencing sperm motility.

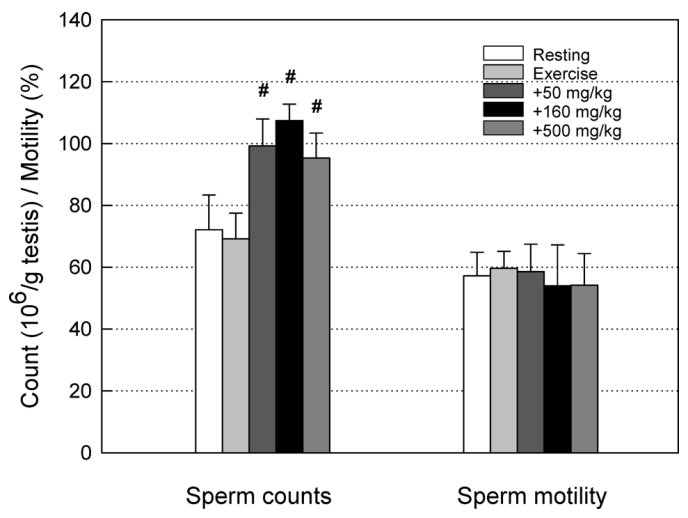

Fig. 4. Testicular Sperm Counts and Epididymal Sperm Motility of Mice Treated with a Silk Amino Acid (SAA) Preparation for 44 d during 30-min Daily Swimming Exercises

The mice were subjected to forced swimming on days 14,28 and 42 . \# Significantly different from exercise (swimming) alone $(p<0.05)$.

\section{DISCUSSION}

Daily 30-min swimming exercise attenuated the body weight gain of mice. In addition, exhaustive forced swimming caused transient body weight loss, which might be due to increased energy consumption. Interestingly, treatment with SAA during exercise further reduced the body weight gain, which was also shown in the resting mice. ${ }^{23)}$ Therefore, it is expected that intake of SAA during exercise synergistically reduces body weight gain.

Repeated swimming exercise increased the maximum swimming time to some extent, indicating an enhanced basic physical strength. Such a stamina-enhancing effect was inferred from the increased mass of gastrocnemius muscles, which is directly related to running ability. Notably, SAA further increased the mass of muscles, in spite of the reduced body weight gain, and thereby markedly improved the swimming ability of mice. It is well known that excessive movement induces lipid peroxidation of tissues including muscles. ${ }^{16,17)}$ Most of all, SAA fully prevented gastricnemius muscles from oxidative injury following exhaustive forced exercise, suggestive of its direct muscle-preserving (anti-oxidant) activity. ${ }^{8,12,16,17)}$ In addition, it is believed that a part of the stamina-improving effect of SAA may come from its anti-fatigue activity, since it recovered blood glucose and proteins depleted by forced swimming exercise. .3,27,30,34) $^{2}$

In addition to loss in body and liver weights related to energy depletion, exercise stress causes damage to various tissues and organs. In the present study, swimming stress decreased the weight of the liver and thymus, but increased 
those of the adrenal glands and gastrocnemius muscles. This stress led to increases in the blood parameters of tissue injury; CPK, BUN, creatinine and lactic acid from the muscles, AST and LDH from the muscles and liver, and ALT from the liver. Notably, SAA markedly recovered the blood parameters of tissue damage, which was also observed in both resting and exercise-stressed animals. ${ }^{22,23)}$ Such effects might be due to its tissue-preserving activities via direct antioxidant or indirect energy-preserving effects, in parallel with previous reports that showed the beneficial effects of branched-chain amino acids on CPK, LDH, lactate, ${ }^{39,40)}$ suggestive of a partial role of branched-chain amino acids included in SAA $(3.49 \%$ Val, $1.25 \%$ Ile and $1.24 \%$ Leu $){ }^{23)}$ In addition, SAA's antioxidant and energy-preserving activities were confirmed from its strong suppressive effects on lipid peroxidation of gastrocnemius muscles and the recovering action on hepatic and muscular glycogen. Tissue glycogen was well preserved by the branched-chain amino acids, although there were controversial results on the role of glycogen in improving exercise performances. ${ }^{40,41)}$ In relation to the muscular adaptation to exercise, the effect of SAA on the mitochondrial change which is regulated by peroxisome proliferator-activated receptor $\gamma$ cofactor- $1 \alpha$ (PGC-1 $\alpha$ ) remains to be further studied. ${ }^{42,43)}$

It is well known that immune systems and adrenal glands are responsive to physical stresses. Forced swimming exercises increased blood corticosterone level, which might be mediated by excessive fatiguing stress. ${ }^{44-46)}$ It is assumed that the decrease in thymus weight resulted from the increased secretion of corticosteroids from the adrenal glands activated by exercise stress. ${ }^{31-33)}$ Interestingly, the decreased weight of the thymus was recovered by treatment with SAA. This presumably occurred by inhibiting the release of immunosuppressive corticosteroids from the adrenal glands. These immunopotentiative and hematopoietic effects of SAA were also observed in resting rats. ${ }^{22)}$

Continuing exercise remarkably lowered the blood concentration of testosterone, which may be due to reduced production under physical stresses. ${ }^{45,47-51)}$ It has previously been demonstrated that increased corticosterone following stress suppressed testosterone secretion. ${ }^{52,53)}$ It is worth noting that SAA not only near-fully reversed the increase in exerciseinduced corticosterone, but also recovered testosterone to a level higher than that of the normal control. Therefore, these results confirmed that SAA facilitated testosterone production, which was indicative of its anti-stress effect as well as action on the synthesis and/or metabolism of steroid hormones from adrenal glands and reproductive organs following amino acids treatment.

SAA tended to increase testes and epididymides weights, and recovered sperm counts reduced by forced swimming exercise, which were in parallel with the increased blood concentration of testosterone. It has been reported that forced swimming stress decreased testosterone secretion, and thereby inhibited spermatogenesis. ${ }^{50,54)}$ Repeated stress activates hypothalamus-pituitary-adrenal axis, suppressing hypothalamus-pituitary-testis axis and male reproductive function. ${ }^{55)}$ Therefore, it is expected that SAA can restore exercise-induced decrease in sperm counts by recovering testosterone level, and thereby improve fertility rates. ${ }^{38,56)}$

In the present study, SAA prolonged maximum swimming time by increasing muscle volume and preventing tissue injury and/or preserving anti-fatigue energy sources. SAA also increased the blood concentration of testosterone, leading to increased sperm counts. Taken together, these results suggest that SAA not only enhances physical stamina by minimizing damage to tissue including muscles as well as preventing energy depletion caused by swimming stress, but also improve male reproductive function by increasing testosterone and sperm counts.

Acknowledgments This work was supported in part by the Korea Research Foundation Grant funded by the Korean Government (KRF-2008-005-J02801).

\section{REFERENCES}

1) Altman G. H., Diaz F., Jakuba C., Calabro T., Horan R. L., Chen J., Lu H., Richmond J., Kaplan D. L., Biomaterials, 24, 401-416 (2003).

2) Lee K. G., Yeo J. H., Lee Y. W., Kweon H. Y., Woo S. O., Han S. M., Kim J. H., Kor. J. Food Ind., 36, 25-37 (2003).

3) Luo J., Chen K., Xu Q., Hirabayashi K., "The Collection of Paper for the Second International Silk Conference," Beijing, 1993, pp. 73-87.

4) Akai H., Shokuhin to Kaihatsu, 34, 43 - 47 (1999).

5) Park K. J., Hong S. E., Do M. S., Hyun C. K., Kor. J. Pharmacogn., 33, 21-28 (2002).

6) Shin M., Park M., Youn M., Lee Y., Nam M., Park I., Jeong Y., J. Korean Soc. Food Sci. Nutr., 35, 1166-1171 (2006).

7) Shin M., Park M., Youn M., Lee Y., Nam M., Park I., Jeong Y., J. Korean Soc. Food Sci. Nutr., 35, 1343-1348 (2006).

8) Lee Y., Park M., Choi J., Kim J., Nam M., Jeong Y., J. Korean Soc. Food Sci. Nutr., 36, 703-707 (2007).

9) Do S.-G., Park J.-H., Kim H.-J., Kim C.-S., Won J.-G., Oh Y. S., Lab. Anim. Res., 6, 157-160 (2007).

10) Hwang E., Kang B., Kim B., Lee H. J., J. Korean Soc. Food Sci. Nutr., 30, 1004-1009 (2001).

11) Tanaka K., Mori K., Mizuno S., J. Biochem., 114, $1-4$ (1993).

12) Lee S. H., Cho H. N., Hyun C. K., Jew S. S., Food Sci. Ind., 35, 57$62(2002)$

13) Nahm J. H., Oh Y. S., RDA J. Agric. Sci., 37, 145-157 (1995).

14) Sugiyama K., Kushima Y., Muramatsu K., Agric. Biol. Chem., 49, 3455-3461 (1985)

15) Kim T, M., Ryu J. M., Seo I. K., Lee K. M., Yeon S., Kang S., Hwang S. Y., Kim Y.-B., Lab. Anim. Res., 24, 67-75 (2008).

16) Kato N., Sato S., Yamanaka A., Yamada H., Fuwa N., Nomura M., Biosci. Biotechnol. Biochem., 62, 145-147 (1998).

17) Zhaorigetu S., Yanaka N., Sasaki M., Watanabe H., Kato N., Oncol. Rep., 10, 537-543 (2003).

18) Ryu J. M., Kim T. M., Seo I. K., Yeon S., Lim W.-T., Lee J.-Y., Hwang S.-Y., O N., Song J., Lee J., Kim Y.-B., Lab. Anim. Res., 24, 361-369 (2008).

19) Moore A. J., Devine D. A., Bibby M. C., Pept. Res., 7, 265-269 (1994).

20) Gotoh K., Izumi H., Kanamoto T., Tamada Y., Nakashima H., Biosci. Biotechnol. Biochem., 64, 1664-1670 (2000).

21) Moore A. J., Beazley W. D., Bibby M. C., Devine D. A., J. Antimicrob. Chemother., 37, 1077-1089 (1996).

22) Kim T, M., Ryu J. M., Seo I. K., Lee K. M., Yeon S., Lim W.-T., Lee J.-Y., Hwang S.-Y., Kim Y.-B., Lab. Anim. Res., 24, 565-573 (2008).

23) Shin S., Park D., Yeon S., Jeon J. H., Kim T. K., Joo S. S., Lim W.-T., Lee J.-Y., Kim Y.-B., Lab. Anim. Res., 25, 127-134 (2009).

24) Estrada-Camarena E., Contreras C. M., Saavedra M., Luna-Baltazar I., Lopez-Rubalcava C., Behav. Brain Res., 134, 175-183 (2002).

25) Griebel G., Simiand J., Serradeil-Le Gal C., Wagnon J., Pascal M., Scatton B., Maffrand J. P., Soubrie P., Proc. Natl. Acad. Sci. U.S.A., 99, $6370-6375$ (2002).

26) Tejani-Butt S., Kluzynski J., Para W. P., Prog. Neuro-Psychopharmacol. Biol. Psychiatry, 27, 7-14 (2003).

27) Koo H.-N., Um J.-Y., Kim H.-M., Lee E.-H., Sung H.-J., Kim I.-K., Int. J. Neurosci., 118, 365-374 (2008).

28) Moriura T., Matsuda U., Kubo M., Biol. Pharm. Bull., 11, 62-66 (1996). 
29) Kim J., Ishibashi M., Nakajima K., Aou S., Hatanaka A., Oomura Y., Sasaki K., Chem. Senses, 30, 266-267 (2005).

30) Wu J. L., Wu G. P., Huang J. M., Chen R., Cai M., Tan J. B., Physiol. Res., 56, 213-220 (2007).

31) Mingoti G. Z., Pereira R. N., Monteiro C. M. R., Brazil. J. Med. Biol. Res., 36, 677-681 (2003).

32) Retana-Marquez S., Bonilla-Jaime H., Vazquez-Palacios G., MartinesGarcia R., Velazquez-Moctezuma J., Horm. Behav., 44, 327-337 (2003).

33) Retana-Marquez S., Bonilla-Jaime H., Vazquez-Palacios G., MartinesGarcia R., Physiol. Behav., 96, 333-342 (2009).

34) Koo H.-N., Lee J.-K., Hong S.-H., Kim H.-M., Biol. Pharm. Bull., 27, $117-119$ (2004).

35) Suzuki Y., Lanner C., Kim J.-H., Vilardo P. G., Zhang H., Yang J., Cooper L. D., Steele M., Kennedy A., Bock C. B., Scrimgeour A., Lawrence J. C. Jr., DePaoli-Roach A. A., Mol. Cell. Biol., 21, 2683 2694 (2001).

36) Kim Y.-B., Oh S. H., Sok D.-E., Kim M. R., Nutr. Neurosci., 7, 33-39 (2004).

37) Shin S., Jeon J. H., Park D., Jang M.-J., Choi J. H., Choi B.-H., Joo S. S., Nahm S.-S., Kim J.-C., Kim Y.-B., Arch. Pharm. Res., 31, 83-87 (2008).

38) Shin S., Park D., Jeon J. H., Joo S. S., Kim Y.-B., Kang H.-G., J. Emb. Trans., 23, 283-289 (2008).

39) Coombes J. S., McNaughton L. R., J. Sports Med. Phys. Fitness, 40 , $240-246$ (2000).

40) de Araujo J. A. Jr., Falavigna G., Rogero M. M., Pires I. S. O., Pedrosa R. G., Castro I. A., Donato J. Jr., Tirapegui J., Life Sci., 79, 1343 1348 (2006).

41) Pederson B. A., Cope C. R., Irimia J. M., Schroeder J. M., Thurberg B.
L., DePaoli-Roach A. A., Roach P. J., Biochem. Biophys. Res. Commun., 331, 491-496 (2005).

42) Arany Z., Curr. Opin. Genet. Dev., 18, 426- 434 (2008).

43) Wright D. C., Han D.-H., Garcia-Roves P. M., Geiger P. C., Jones T. E., Holloszy J. O., J. Biol. Chem., 282, 194-199 (2007).

44) Millan M. J., Przewlocki R., Jerlics M., Gramsch C. H., Holt V., Herz A., Brain Res., 208, 325-338 (1981).

45) Dufau M. L., Tinajero J. C., Fabbri A., FASEB J., 7, 299-307 (1993).

46) Byun S. L., Lee Y. E., Shin S., Jang J. Y., Choi B., Park D. Jeon J. H., Nahm S.-S., Hwang S.-Y., Kim Y.-B., Lab. Anim. Res., 23, 127-131 (2007).

47) Collu R., Gibb W., Bichet D. G., Ducharme J. R., Endocrinology, 115, 1609-1615 (1984)

48) Collu R., Gibb W., Ducharme J. R., J. Endocrinol. Invest., 7, 529-537 (1984).

49) Remes K., Kuoppasalmi K., Adlercreut H., Int. J. Sports Med., 6, $131-135$ (1985)

50) Bidzinska B., Petraglia F., Angioni S., Genazzani A. D., Risculolo M., Ficarra G., Gallinelli A., Trentini G. P., Genazzani A. R., Neuroendocrinology, 57, 985-990 (1993).

51) Kant P. A., Saxena R. N., Indian J. Exp. Biol., 33, 165-168 (1995).

52) Abbott D. H., Holman S. D., Berman M., Neff D. A., Goy R. W., Arch. Sex. Behav., 13, 1-25 (1984).

53) Taylor G. T., Weiss J., Rupich R., Physiol. Behav., 39, 429-433 (1987).

54) Chapman D. P., Perry G. S., Prev. Chronic Dis., 5, A22 (2008).

55) Rehman H. U., Masson E. A., Gend. Med., 2, 41-56 (2005).

56) Gasco M., Aguilar J., Gonzales G. F., Andrologia, 39, 151-158 (2007). 